\title{
Modeling of heat flow using commercial and authorial software on the example of a permanent magnet motor
}

\author{
Elżbieta Gawrońska ${ }^{1, *}$, Robert Dyja ${ }^{1}$, Barttomiej Będkowski ${ }^{2}$, and Lukasz Cyganik ${ }^{2}$ \\ ${ }^{1}$ Faculty of Mechanical Engineering and Computer Science, Czestochowa University of Technology, \\ Dabrowskiego 69, 42-201 Czestochowa, Poland \\ ${ }^{2}$ Institute of Electrical Drives and Machines KOMEL, Sosnowiec, Poland
}

\begin{abstract}
The aim of the work is the modeling of the heat flow in an electric motor with permanent magnets with a height of $56 \mathrm{~mm}$. Numerical calculations were carried out for a simplified 3D model prepared in the Autodesk Inventor solid modeling program. The bodies were prepared from the existing model and constructional documentation of the actual engine. In the next step, the simplified solid model was imported into a commercial Autodesk Simulation Multiphysics computing package and into authorial software in which it was supplied with appropriate material properties and discretized. In the next stage, the model was calibrated and verified by a preheating attempt of the actual object. The motor winding was supplied with direct current and was a heat source with a power of $40 \mathrm{~W}$. Temperatures were recorded at selected points in the steady state. Then, on a discredited numerical model, computer simulations corresponding to the actual heating test were carried out. When comparing the temperature values obtained at the points corresponding to the measurement points, the model was calibrated, which corrected the thermal resistance parameters assumed in the calculation model. Finally, the model (after the implemented changes) was verified with results obtained with commercial and authorial software.
\end{abstract}

Keywords: heat flow, electric motor, temperature field, numerical modeling, computer simulation

\section{Introduction}

Numerical simulations of heat flow are increasingly used to solve thermal problems that arise during machine's designing in many branches of industry. One of the branches of engineering where tools for numerical analysis of heat flow are widely used is electrical engineering and designing of electrical machines. A very important component of each electrical machine is an efficient cooling system that ensure appropriate heat dissipation generated by electrical circuits $[1,2]$. Designing of such a cooling system for electrical machines requires increasingly accurate tools that allow modeling of heat flow in changing environmental

\footnotetext{
* Corresponding author: gawronska@icis.pcz.pl

Reviewers: Janusz Mielniczuk, Josef Soukup
} 
conditions [3, 4]. A further thermal diagnostics that allow to identify problems with malfunctioning cooling system is a difficult and time-consuming issue $[5,6]$. Therefore, the accuracy of heat flow numerical simulations at the phase of electrical machine's designing is a very important factor determining the subsequent operation of the machine. In addition, in engineering practice a very important aspect beside the accuracy of thermal simulation is the simplicity of the tools for the simulation of heat flow that allows to reduce the performing time of numerical simulation. Therefore, there is a need for development and improvement of heat flow simulation tools dedicated to electrical machines.

In the paper, we present the temperature distribution caused by the heat flow in an electric motor with permanent magnets. Numerical calculations were carried out for a simplified 3D model prepared in the Autodesk Inventor solid modeling program. The bodies were prepared on the basis of the existing model and constructional documentation of the actual engine. In the next step, the simplified solid model was imported into a commercial Autodesk Simulation Multiphysics computing package and into authorial software in which it was supplied with appropriate material properties and discretized. In the commercial software, the model was calibrated and verified on the basis of a preheating attempt of the actual object. In the proprietary software, the calculations were carried out on in the same conditions. Finally, the verification of the obtained temperature distribution was carried out.

\section{Methods}

Finite element formulation (FEM) is derived from the equation of heat conduction with temperature dependent conductivity and heat capacity. The derivation of the finite element model is based on a variational formulation of the heat conduction equation which, together with generalized coordinates, yields an equation of similar form to Lagrange's equation in mechanics. The obtained equation is of particular interest for applying the finite element method to solve problems with temperature-dependent properties [7].

If we know the internal temperature distribution for a given moment in time, we can calculate the heat flux in every single point by Fourier's law (PDE - Partial Differential Equation). Heat conduction is described by a quasi-linear equation, considering a term of heat source $q$ :

$$
\nabla \cdot(\lambda \nabla T)+\dot{q}=c \rho \frac{\partial T}{\partial t}
$$

where: $\lambda$ is a thermal conductivity coefficient, $T$ is temperature, $c$ is specific heat, $\rho$ is a density of the material and $\frac{\partial T}{\partial t}$ the partial derivative of the temperature with respect to time.

In our calculations we use steady state problem and the Cauchy boundary condition (boundary condition of the third type):

$$
-\lambda \frac{\partial T}{\partial n}=\alpha\left(T-T_{r e f}\right)
$$

where $T_{r e f}$ is the surrounding temperature, $n$ is a normal vector component, and $\alpha$ is a heat transfer coefficient or Newton coefficient. Very often, there is a thermal interaction between the body and the surrounding temperature, so to quantify that interaction, the boundary of the domain is considered as a control "volume" for an energy balance. Since the thickness of the boundary is zero, no energy can be stored within what means that all the heat entering a surface increment from the interior (by conduction) has to leave outwards (by convection) [8].

In our calculations, we use FEM and Petrov-Galerkin formulation which transform Eq.1 to the algebraic system of equations. The assembling procedure of the global system of ordinary differential equations (ODE) is equivalent to transforming the local element matrices into the global element matrices. Then these matrices are assembled: 


$$
[\mathbf{M}]\{\dot{\mathbf{T}}\}+[\mathbf{K}]\{\mathbf{T}\}=\{\mathbf{b}\}
$$

where $\mathbf{M}$ is the global capacitance matrix, $\mathbf{K}$ is the global stiffness matrix, $\mathbf{b}$ is right-handside vector, vectors $\{\dot{\mathbf{T}}\},\{\mathbf{T}\}$ and $\{\dot{\mathbf{b}}\}$ denote the derivatives of the temperature with respect to time for all the nodes, the nodal temperatures and nodal loads, respectively. The assembly procedure avoids adding 0 terms and makes the algorithm effective for large and sparse matrices.

Simulation tools become indispensable for engineers who are interested in tackling increasingly larger problems or the ones who are interested in searching larger phase space of process and system variables to find the optimal design. Advances in hardware allow not only to solve the larger tasks (using more detailed grids) but also to describe the problem more accurately. Increasing capacity of computer memory makes it possible to consider growing problem sizes. At the same time, increased precision of simulations triggers even higher load. There are several ways to tackle these kinds of problems. For instance, one can use parallel computing [9], someone else may use accelerated architectures such as GPUs [10], while another person can use the unique organization of computations [11]. We have used parallel processing to assure sufficient time duration for simulations. During the implementation, we used TalyFem and PETSc libraries, which allowed us to split structures, such as matrices and vectors, into many computing nodes $[12,13]$.

In general, the method of the research consisted of (i) conducting an experimental heating test of an actual stator of the electrical motor equipped with the bearing endshields and the base plate, (ii) calibration of the numerical model based on the results of the experiment and finally (iii) conducting a numerical simulations on a calibrated numerical model using two types of software: authorial and commercial. The experimental heating test consisted of supplying the stator's winding with direct current and measuring the temperature at several points after reaching a steady state of the heat flow. During direct current supply, heat is generated only in the stator winding, therefore the number of heat sources is reduced to only one. Performing numerical analysis for simple boundary conditions reflecting direct current supply, the numerical model can be easily calibrated. The calibration is carried out by selecting the thermal resistance values between the individual components of the model in such a way to achieve the difference between steady-state temperatures measured in an experiment and numerically determined as small as possible, thus calibrated numerical model can be used to conduct further numerical analysis for other boundary conditions.

\section{Numerical simulations and validation}

\subsection{Experimental heating test}

The actual stator of the electric motor equipped with the bearing endshields and the base plate was subjected to the heating test. Such an experimental model was equipped with seven temperature sensors. The location of the temperature sensors was presented in the Fig. 1. The stator winding was supplied with a direct current of $14.9 \mathrm{~A}$ and the voltage of $2.7 \mathrm{~V}$. The stator was powered to achieve the steady state of the heat flow. The ambient temperature during the heating test was $21^{\circ} \mathrm{C}$. 

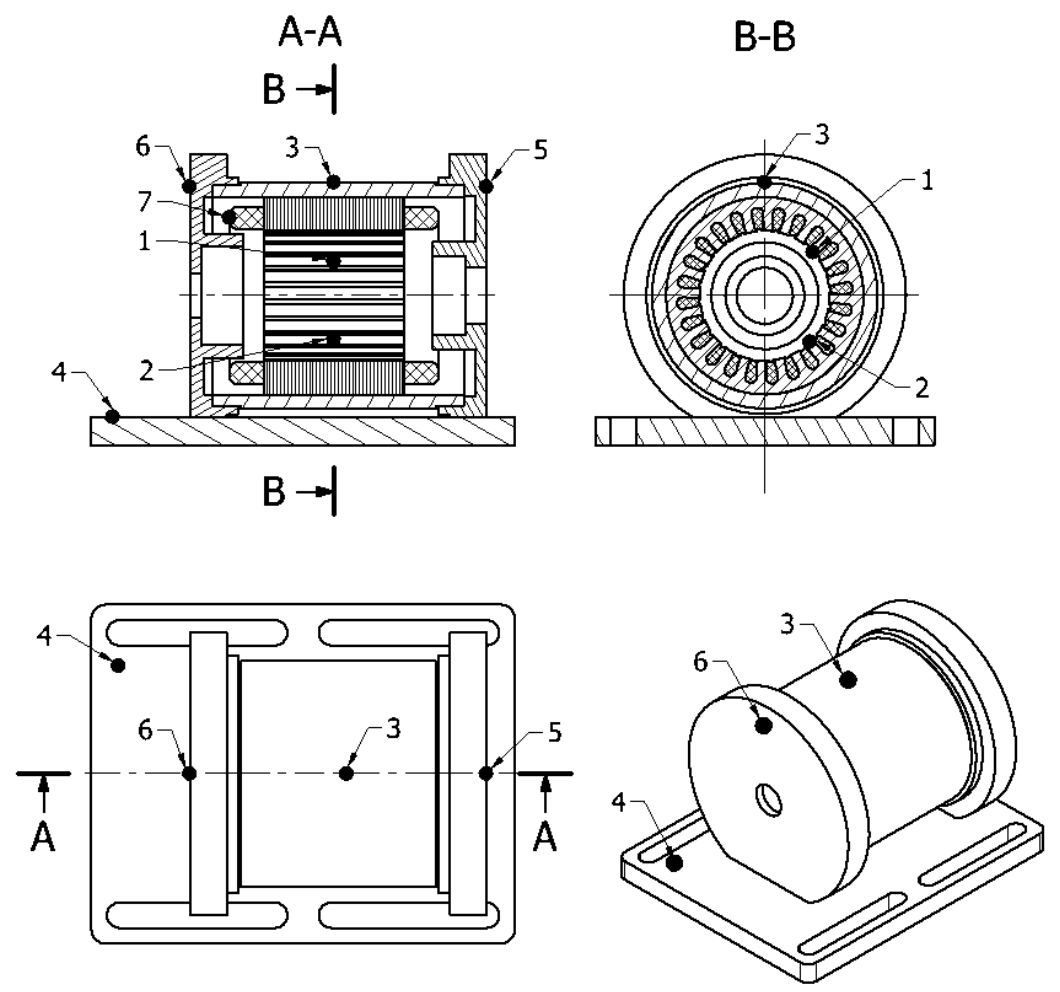

Fig. 1. The location of the temperature sensors

\subsection{Numerical model parameters and calibration}

The simplified 3D model of the stator equipped with the bearing endshields and the base plate was prepared in the Autodesk Inventor solid modeling program. The visualization of the 3D model is presented in Fig. 1. The 3D model was used to create the numerical model for the heat flow simulations performed in the Autodesk Simulation Multiphysics computing package. The material parameters assigned to the winding, stator stack, stator frame, bearing endshields and the base plate in the numerical model are shown in Table 1. In the numerical model, the stator's interior was filled with air.

From the experimental results of the heating tests, the thermal resistance value in the numerical model on the border of individual electric motor components was established. The thermal resistance value was estimated based on the minimization of the difference between the temperatures determined experimentally and numerically at all measuring points in the steady state of the heat flow. The numerically estimated temperatures obtained through a calibrated numerical model for all measurement points in a steady state of the heat flow are presented in Table 2. Finally, the thermal resistance value between the stator's winding and stator stack was estimated as $0.009 \mathrm{~K} \cdot \mathrm{m}^{2} / \mathrm{W}$. For all other connections, the thermal resistance value was the same, and it was $0.00009 \mathrm{~K} \cdot \mathrm{m}^{2} / \mathrm{W}$. 
Table 1. The material parameters assigned to the numerical model.

\begin{tabular}{|c|c|c|c|c|c|c|c|}
\hline \multirow[b]{2}{*}{ No. } & \multirow[b]{2}{*}{$\begin{array}{l}\text { Material } \\
\text { parameter } \\
\text { value }\end{array}$} & \multirow[b]{2}{*}{ Axis } & \multicolumn{5}{|c|}{ Components of the electrical motor } \\
\hline & & & $\begin{array}{l}\text { stator frame/ } \\
\text { endshields } \\
\text { (aluminum) }\end{array}$ & $\begin{array}{c}\text { stator } \\
\text { stack } \\
\text { (electrical } \\
\text { steel) }\end{array}$ & $\begin{array}{l}\text { winding } \\
\text { (copper) }\end{array}$ & $\begin{array}{l}\text { base plate } \\
\text { (steel) }\end{array}$ & air \\
\hline 1 & $\begin{array}{l}\text { Density } \\
{\left[\mathrm{g} / \mathrm{cm}^{3}\right]}\end{array}$ & $X, Y, Z$ & 2.7 & 7.8 & 8.96 & 7.8 & $\begin{array}{l}\text { equation } \\
\text { of state }\end{array}$ \\
\hline \multirow{3}{*}{2} & \multirow{3}{*}{$\begin{array}{c}\text { Conductivity } \\
{[\mathrm{W} / \mathrm{m} \cdot \mathrm{K}]}\end{array}$} & $\mathrm{X}$ & \multirow{3}{*}{204} & 30 & 0.45 & \multirow{3}{*}{$\begin{array}{c}\text { Piecewise } \\
\text { linear: } \\
55\left(0^{\circ} \mathrm{C}\right) \text { - } \\
31 \\
\left(1200^{\circ} \mathrm{C}\right)\end{array}$} & \multirow{3}{*}{0.02563} \\
\hline & & $\mathrm{Y}$ & & 30 & 1.5 & & \\
\hline & & $\mathrm{Z}$ & & 3 & 290 & & \\
\hline 3 & $\begin{array}{c}\text { Specific heat } \\
{[\mathrm{J} / \mathrm{kg} \cdot \mathrm{K}]}\end{array}$ & $\mathrm{X}, \mathrm{Y}, \mathrm{Z}$ & 896 & 465 & 380.7 & 465 & 1000 \\
\hline 4 & Emissivity & $\mathrm{X}, \mathrm{Y}, \mathrm{Z}$ & 0.2 & 0.3 & 0.6 & 0.3 & \\
\hline 5 & $\begin{array}{c}\text { Dynamic } \\
\text { viscosity } \\
{[\mathrm{Pa} \cdot \mathrm{s}]}\end{array}$ & $\mathrm{X}, \mathrm{Y}, \mathrm{Z}$ & - & - & - & - & $1.8 \cdot 10^{-5}$ \\
\hline
\end{tabular}

\subsection{Numerical simulations}

The results of temperature measurements in the steady state of the heat flow are presented in Table 2 (for the experiment, and numerical simulations carried out in commercial and noncommercial software, respectively). In the numerical simulations conducted by both kind of the software, the physical properties were also taken according to Table 1 .

Table 2. The results of temperature measurements in the heating test

\begin{tabular}{|c|c|c|c|c|}
\hline $\begin{array}{c}\text { Sensor } \\
\text { number }\end{array}$ & $\begin{array}{c}\text { Location of } \\
\text { the sensor }\end{array}$ & $\begin{array}{c}\text { Experimentally } \\
\text { measured } \\
\text { temperature in } \\
\text { the steady state }\end{array}$ & $\begin{array}{c}\text { Numerically } \\
\text { estimated } \\
\text { temperature in } \\
\text { the steady state } \\
\text { (commercial) }\end{array}$ & $\begin{array}{c}\text { Numerically } \\
\text { estimated } \\
\text { temperature in } \\
\text { the steady state } \\
\text { (authorial) }\end{array}$ \\
\hline 1 & stator tooth & $54.8^{\circ} \mathrm{C}$ & $54.79^{\circ} \mathrm{C}$ & 54.28 \\
\hline 2 & stator tooth & $54.9^{\circ} \mathrm{C}$ & $54.79^{\circ} \mathrm{C}$ & 54.01 \\
\hline 3 & stator frame & $52.5^{\circ} \mathrm{C}$ & $53.77^{\circ} \mathrm{C}$ & 53.48 \\
\hline 4 & base plate & $48.4^{\circ} \mathrm{C}$ & $46.7^{\circ} \mathrm{C}$ & 46.54 \\
\hline 5 & $\begin{array}{c}\text { drive } \\
\text { endshield }\end{array}$ & $52.7^{\circ} \mathrm{C}$ & $51.48^{\circ} \mathrm{C}$ & 51.39 \\
\hline 6 & $\begin{array}{c}\text { non drive } \\
\text { endshield }\end{array}$ & $51.4^{\circ} \mathrm{C}$ & $51.41^{\circ} \mathrm{C}$ & 51.51 \\
\hline 7 & winding & $63.58^{\circ} \mathrm{C}$ & $64.02^{\circ} \mathrm{C}$ & 54.55 \\
\hline
\end{tabular}

The results obtained in the heating test were used to calibrate the numerical model of the electrical motor. The aim of the calibration was an improvement of the thermal resistance 
value in the numerical model. The temperature fields obtained by commercial and authorial software are presented in Fig. 4 and Fig. 5.

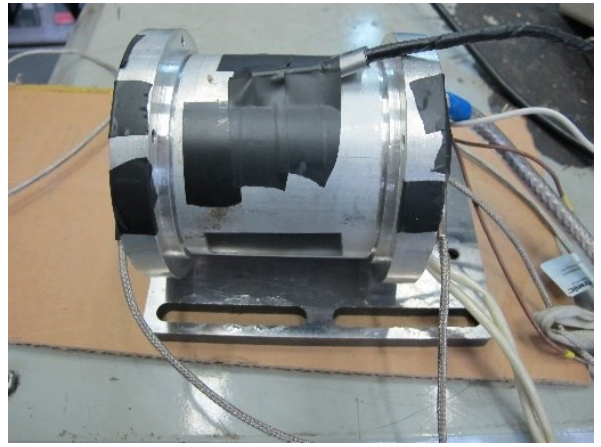

a)

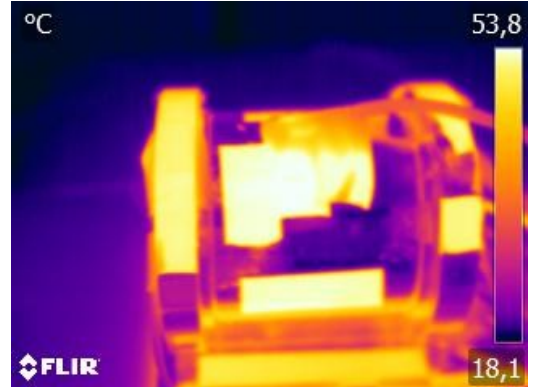

b)

Fig. 2. Thermal camera image (b) of the temperature distribution for physical model (a)

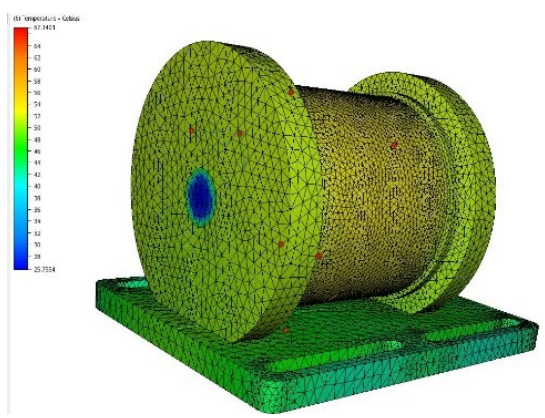

a)

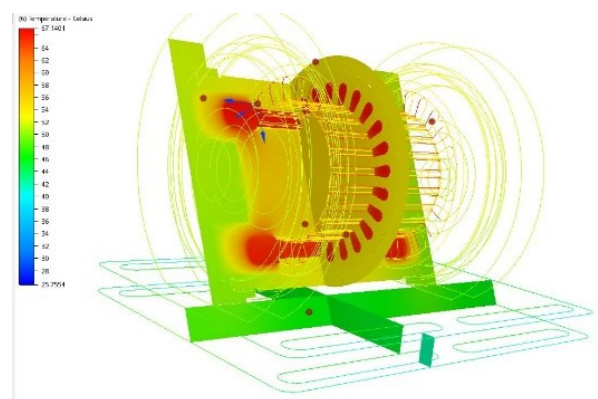

b)

Fig. 3. Finite element mesh (a) and the temperature measurement point (b) for electric motor under consideration

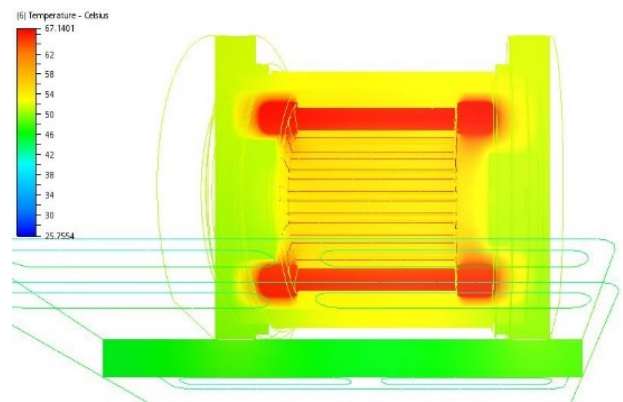

a)

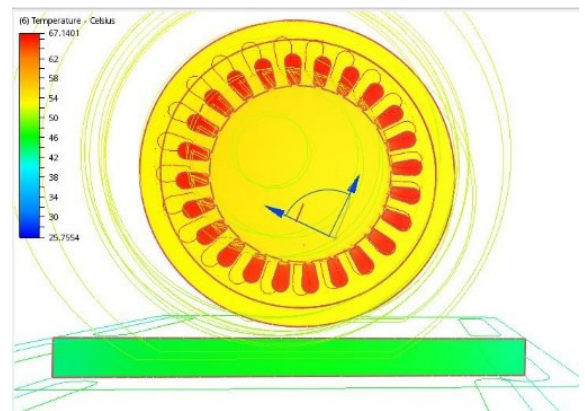

b)

Fig. 4. Temperature distribution obtained from commercial software 


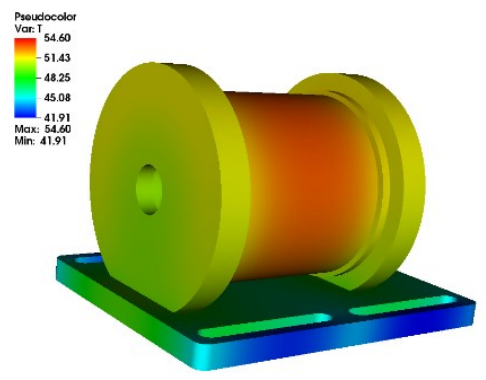

a)

c)

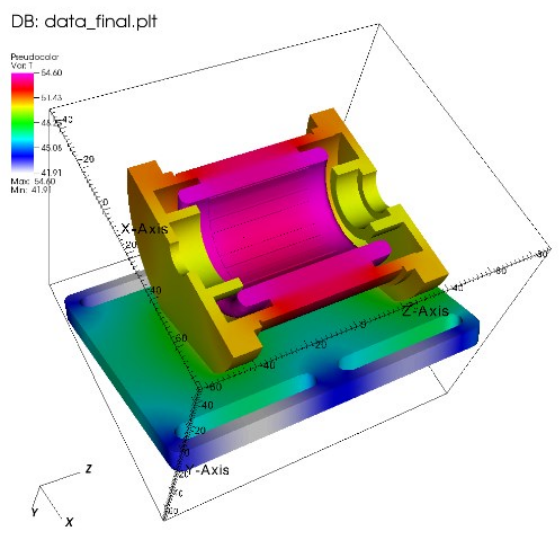

Fig. 5. Temperature distribution obtained from non-commercial software

\section{Conclusions}

The goal of the work was the modelling of the heat flow in an electric motor with permanent magnets. The paper presents temperature distributions obtained as a result of numerical simulations performed using the commercial and proprietary software. Experimental validation of temperature fields obtained as a result of numerical calculations showed that in both computation cases results are convergent (except temperature in winding where there are little discrepancies), which in turn is the basis for further development of authorial software. In the future work, it is necessary to find the reason for the difference in computing temperature of winding. This kind of work makes sense, especially from the scientific point of view and innovative solutions for selected problems of thermomechanics connected with permanent magnet motors. 


\section{References}

1. S. Gawron, J. Bernatt and P. Dukalski, "Modelowanie 3D prądnicy ze wzbudzeniem hybrydowym," Maszyny Elektryczne - Zeszyty Problemowe, 3(91), 199-204 (2011)

2. S. Gawron, "Wybrane, innowacyjne projekty maszyn elektrycznych z magnesami trwałymi i ich praktyczne zastosowania," Maszyny Elektryczne - Zeszyty Problemowe, 1(109), 1-10, (2016)

3. B. Będkowski and J. Madej, "The potential of 3D FEM and CFD methods for cooling systems analysis of electrical machines - the premises," Maszyny Elektryczne - Zeszyty Problemowe, 1(94), 139-143, (2012)

4. J. Madej and B. Będkowski, "Air flow analysis for electrical motor's cooling system with Autodesk Simulation CFD 2013 Program," Acta mechanica et automatica, 2, 8992 (2013)

5. M. Barański and A. Polak, "Thermographic diagnostic of electrical machines," in The XIX International Conference on Electrical Machines - ICEM 2010, Rome (2014)

6. M. Barański and A. Polak, "Thermal diagnostic in electrical machines," Przegląd elektrotechniczny, 10, 305-308 (2011)

7. G. A. Keramidas, "Finite element of the heat conduction equation with temperature dependent coefficients," Mathematics and Computers in Simulation, 22, 3, 248-255 (1980)

8. B. Pentenrieder, "Finite Element Solutions of Heat Conduction Problems in Complicated 3D Geometries Using the Multigrid Method," Fakultat fur Informatik, TU Munchen, Munich, Germany (2005)

9. Q. Xu, B. Liu and W. Feng, "Microstructure simulation of aluminum alloy using parallel computing technique," ISIJ International, 42, 7, 702-707 (2002)

10. L. Klimes and J. Stetina, "A rapid GPU-based heat transfer and solidification model for dynamic computer simulations of continuous steel casting," Journal of Materials Processing Technology, 226, 1-14 (2015)

11. E. Gawronska and N. Sczygiol, "Application of mixed time partitioning methods to raise the effciency of solidification modeling," in in 12th International Symposium on Symbolic and Numeric Algorithms for Scientific Computing (SYNASC 2010), Timisoara, Romania (2011)

12. S. Balay, S. Abhyankar, M. F. Adams and e. al., "PETSc users manual, Tech. Rep. ANL-95/11 - Revision 3.7," Argonne National Laboratory, 2016. [Online]. Available: http://www.mcs.anl.gov/petsc. [Accessed 1607 2018].

13. H. K. Kodali and B. Ganapathysubramanian, "A computational framework to investigate charge transport in heterogeheterogeneous," Computer Methods In Applied Mechanics And Engineering, 247, 113-129, (2012)

14. "https://www.cgal.org/," [Online]. Available: https://www.cgal.org/. [Accessed 2308 2017].

15. E. Gawronska and N. Sczygiol, in 12th Internaitonal Symposium on Symbolic and Numeric Algorithms for Scientific Computing (SYNASC 2010), Timisoara (2011) 